\title{
Research and Exploration on Computation and Countermeasures on Cloud, Fog and Rain Attenuation in Ka-band Satellite Communication
}

\author{
Zhiyi Xiao, Ziyun Wang and Yi Sun* \\ School of Software Engineering, State Key Laboratory of Networking and Switching Technology Beijing University of Posts and \\ Telecommunications, Beijing 100876, China \\ *Corresponding author
}

\begin{abstract}
Satellite communication system design engineers are often concerned with the attenuation caused by propagation in rainfall while ignoring the influence on microwave propagation on satellite-earth link in satellite communication on cloudy, foggy or rainy days. This paper comprehensively gives a calculation method in satellite communication attenuation in the Ka-band. The method can be used as reference for researchers engaged in similar work. In this paper, we analyze the effects of cloud, fog and rain attenuation in Ka-band satellite communication. We also suggest real-time dynamic compensation uplink and fixed rain compensation downlink by rate diversity technology. As a result, this method compensates for cloud, fog and rain attenuation and simplifies satellite control.
\end{abstract}

Keywords—attenuation; Ka-band; link; compensation

\section{INTRODUCTION}

In the design of satellite-earth link, engineers are often concerned about the rainfall in where the ground station is located. Then, they could calculate the appropriate link margin, and ensure the stable connection of the link under certain climatic conditions. However, most engineers do not consider the impact of cloud, rain and fog have on the radio wave propagation. The impact has become a forgotten area in satelliteearth link design in satellite communication. This paper aims to analyze the impact cloud, rain and fog have on satellite-earth link in satellite communication, especially in Ka-band.

\section{ANALYSIS OF Cloud AND Fog AtTENUATION IN RADiO WAVE TRANSMISSION}

\section{A. Cloud and Fog Attenuation Coefficient}

Cloud and fog attenuation coefficient can be expressed by $\mathrm{K}_{1}$. The absorption of radio waves by the cloud and fog is mainly related to liquid water in cloud and fog. Therefore, cloud and fog attenuation is mainly related to the dielectric constant of liquid water in the cloud and fog.

Dielectric constant of water [1]:

$$
\begin{aligned}
& \varepsilon^{\prime}(f)=\frac{f\left(\varepsilon_{0}-\varepsilon_{1}\right)}{\left[1+\left(f / f_{p}\right)^{2}\right]}+\frac{f\left(\varepsilon_{1}-\varepsilon_{2}\right)}{\left[1+\left(f / f_{s}\right)^{2}\right]}+\varepsilon_{2} \\
& \varepsilon^{n}(f)=\frac{f\left(\varepsilon_{0}-\varepsilon_{1}\right)}{f_{p}\left[1+\left(f / f_{p}\right)^{2}\right]}+\frac{f\left(\varepsilon_{1}-\varepsilon_{2}\right)}{f_{s}\left[1+\left(f / f_{s}\right)^{2}\right]}
\end{aligned}
$$

Where, $\varepsilon_{0}=77.6+103.3(\theta-1), \varepsilon_{1}=5.48, \varepsilon_{2}=3.51, \theta=\frac{300}{\mathrm{~T}}, \mathrm{~T}$ is

temperature $(\mathrm{K}), \mathrm{f}_{\mathrm{p}}=20.09-149(\theta-1)+249(\theta-1)^{2}, \mathrm{f}_{\mathrm{s}}=590-1500(\theta-1)$

According to Recommendation of ITU-R $840.3, \mathrm{~K}_{1}$ can be expressed as equation (3) [1]

$$
\mathrm{K}_{\mathrm{l}}=\frac{0.819 \mathrm{f}}{\varepsilon^{\mathrm{n}}\left(1+\eta^{2}\right)}
$$

Where $\mathrm{f}$ is frequency $(\mathrm{GHz})$, and $\eta=\frac{2+\varepsilon^{\prime}}{\varepsilon^{\mathrm{n}}}$

B. Calculation of Cloud and Fog Attenuation

The cloud and fog attenuation of the satellite-earth link is related to the antenna elevation angle of the ground station. Supposing the antenna elevation angle of the ground station is $\theta$, the cloud and fog attenuation of the satellite-earth link is: [1]

$$
A=\frac{L K_{1}}{\sin \theta} d B \text { for } 90^{\circ} \geq \theta \geq 5^{\circ}
$$

Where $\theta$ is the elevation angle, $\mathrm{L}$ is water vapor content in gas column in $\left(\mathrm{kg} / \mathrm{m}^{2}\right)$

\section{RAIN ATtENUATION VALUE ON SATELLITE-EARTH LiNK IN KA-BAND SATELLITE COMMUNICATION}

From (4),

$$
\theta=\arcsin \frac{L K_{1}}{\mathrm{~A}}
$$

Rain attenuation coefficient $\gamma_{R}$ can be obtained from (6) [2]

$$
\gamma_{\mathrm{R}}=\mathrm{kR}^{\alpha}
$$

$\mathrm{k}$ and $\alpha$ are related to the operating frequency and polarization,

For circular polarization and arbitrary linear polarization 


$$
\begin{array}{r}
\mathrm{k}=\frac{\left[\mathrm{k}_{\mathrm{H}}+\mathrm{k}_{\mathrm{V}}+\left(\mathrm{k}_{\mathrm{H}}-\mathrm{k}_{\mathrm{V}}\right) \cos ^{2} \theta \cos 2 \tau\right]}{2} \\
\alpha=\frac{\left[\mathrm{k}_{\mathrm{H}} \alpha_{\mathrm{H}}+\mathrm{k}_{\mathrm{V}} \alpha_{\mathrm{V}}+\left(\mathrm{k}_{\mathrm{H}} \alpha_{\mathrm{H}}-\mathrm{k}_{\mathrm{V}} \alpha_{\mathrm{V}}\right) \cos ^{2} \theta \cos 2 \tau\right]}{2 \mathrm{~K}}
\end{array}
$$

Substituting (5) into (7) (8),

$$
\begin{gathered}
\mathrm{k}=\frac{\left[\mathrm{k}_{\mathrm{H}}+\mathrm{k}_{\mathrm{V}}+\left(\mathrm{k}_{\mathrm{H}}-\mathrm{k}_{\mathrm{V}}\right)\left(1-\left(\frac{\mathrm{LK}}{\mathrm{A}}\right)^{2}\right) \cos 2 \tau\right]}{2} \\
\alpha=\frac{\left[\mathrm{k}_{\mathrm{H}} \alpha_{\mathrm{H}}+\mathrm{k}_{\mathrm{V}} \alpha_{\mathrm{V}}+\left(\mathrm{k}_{\mathrm{H}} \alpha_{\mathrm{H}}-\mathrm{k}_{\mathrm{V}} \alpha_{\mathrm{V}}\right)\left[1-\left(\frac{\mathrm{LK} \mathrm{K}_{1}}{\mathrm{~A}}\right)^{2}\right] \cos 2 \tau\right.}{2 \mathrm{~K}}
\end{gathered}
$$

Where $\tau$ is the angle between the polarization direction of the link line and the horizontal plane. When the link polarization is circularly polarized, $\tau$ is $45^{\circ} . \mathrm{k}_{\mathrm{H}}, \mathrm{k}_{\mathrm{V}}, \alpha_{\mathrm{H}}$ are the values of horizontal and vertical linear polarization, respectively. $\theta$ is the working station elevation angle

The effective path length of the electric wave $\mathrm{L}_{\mathrm{E}}$ passing through the rain zone can be obtained by the formula (11) [2]

$$
\mathrm{L}_{\mathrm{E}}=\mathrm{L}_{\mathrm{P}} \mathrm{V}_{\mathrm{P}}
$$

Where $L_{P}$ is the attenuation path of the electric wave passing through the rainfall zone, $\mathrm{v}_{\mathrm{p}}$ is the vertical height adjustment coefficient at the availability (1-p\%), $\mathrm{p} \%$ is the probability of the link interruption.

At the availability of $99.99 \%$, the vertical height adjustment coefficient $\mathrm{v}_{\mathrm{S}}$ can be obtained from (12) [2]

$$
\mathrm{V}_{\mathrm{s}}=\frac{1}{1+\sqrt{\sin \theta}\left(31\left(1-\mathrm{e}^{-\left(\frac{\theta}{1+\chi}\right)}\right) \frac{\sqrt{\mathrm{L}_{\mathrm{P}} \gamma_{\mathrm{R}}}}{\mathrm{f}^{2}}-0.45\right)}
$$

Substituting equation (5) into equation (12)

$$
\mathrm{k}=\frac{1}{1+\sqrt{\frac{\mathrm{LK}_{1}}{\mathrm{~A}}}\left(31\left(1-\mathrm{e}^{-\left(\frac{\arcsin \frac{\mathrm{LK}_{\mathrm{I}}}{\mathrm{A}}}{1+\chi}\right)}\right) \frac{\sqrt{\mathrm{LP}_{\mathrm{P}} \gamma_{\mathrm{R}}}}{\mathrm{f}^{2}} 0.45\right)}
$$

Where $\mathrm{f}$ is the link operating frequency; $\chi$ is related to the latitude of the earth station. When the latitude is $|\varphi|<36^{\circ}, \chi=36-$ $|\varphi|$ (unit: degree)

When the earth station latitude $|\varphi| \geq 36^{\circ}, \chi=0^{\circ}$

The attenuation path length of the electric wave $L_{P}$ (unit: $\mathrm{km}$ ) passing through the rainfall zone can be obtained from equations (15) (16) [2]

When

$$
\zeta>\theta\left(\zeta=\arctan \left(\frac{\mathrm{h}_{\mathrm{R}}-\mathrm{h}_{\mathrm{s}}}{\mathrm{L}_{\mathrm{s}} \mathrm{r}_{\mathrm{s}}}\right)\right), \mathrm{L}_{\mathrm{P}}=\mathrm{L}_{\mathrm{s}} \mathrm{r}_{\mathrm{s}}
$$

When

$$
\zeta \leq \theta, \mathrm{L}_{\mathrm{P}}=\frac{\mathrm{h}_{\mathrm{R}}-\mathrm{h}_{\mathrm{s}}}{\sin \theta}
$$

$h_{R}$ is the height of the rainfall zone through which the link traverses, and $h_{s}$ is the altitude of the earth station.

When the elevation angle of the earth station $\theta \geq 5^{\circ}$, the path of the electric wave passing through the rainfall zone $\mathrm{L}_{\mathrm{s}}$ can be obtained by equation (16)[2]

$$
\mathrm{L}_{\mathrm{s}}=\frac{\mathrm{h}_{\mathrm{R}}-\mathrm{h}_{\mathrm{s}}}{\sin \theta}
$$

At link availability of $99.99 \%$, horizontal path attenuation coefficient $r_{s}$ can be obtained from equation (17) [2]

$$
r_{s}=\frac{1}{1+0.78 \sqrt{\frac{L_{\mathrm{P} \gamma_{\mathrm{R}}}}{\mathrm{f} \cos \theta}}-0.38\left(1-\mathrm{e}^{-2 \mathrm{~L}_{\mathrm{S}} \cos \theta}\right)}
$$

Substituting equation (5) into equation (17)

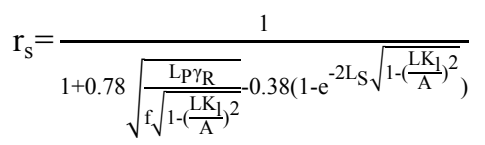

Then, total rainfall attenuation at availability 99.99\% [2]

$$
\mathrm{L}_{\mathrm{Rs}}=\gamma_{\mathrm{R}} \mathrm{L}_{\mathrm{P}} v_{\mathrm{s}}
$$

For the availability of $99.999 \%$ to $95 \%$, rain attenuation $L_{R}$ can be obtained from equation (18)[2]:

$$
\mathrm{L}_{\mathrm{R}}=\mathrm{L}_{\mathrm{Rs}}\left(\frac{\mathrm{p}}{0.01}\right)^{-\left(0.655+0.033 \ln \mathrm{p}-0.045 \ln \mathrm{L}_{\mathrm{Rs}}-\beta(1-\mathrm{p}) \sin \theta\right)}
$$

Substituting equation (5) into equation (21) comes out a cloud, fog and rain attenuation with the availability of $99.999 \%$ to $95 \%$.

$$
\mathrm{L}_{\mathrm{R}}=\mathrm{L}_{\mathrm{Rs}}\left(\frac{\mathrm{p}}{0.01}\right)^{-\left(0.655+0.033 \ln \mathrm{p}-0.045 \ln \mathrm{L}_{\mathrm{Rs}} \frac{\beta(1-\mathrm{p}) \mathrm{LK}_{\mathrm{K}}}{\mathrm{A}}\right)}
$$

$\beta$ is related to the link availability and the latitude of the earth station.

When the availability is not more than $99 \%$ or the latitude of the earth station $|\varphi| \geq 36^{\circ}, \beta=0$.

When availability is greater than $99 \%$, and the latitude of the earth station $|\varphi|<36^{\circ}$ :

when the earth station's elevation angle $\theta \geq 25^{\circ}, \beta=-0.05(|\varphi|-36)$;

otherwise

$\beta=-0.05(|\varphi|-36)+1.8-4.25 \sin \theta=-0.05(|\varphi|-36)+1.8-4.25 \sin \theta$

\section{Cloud, FOG AND RAIN ATtENUATION COMPENSATION STRATEGY}

\section{A. Rate Diversity Technology}

The signal to noise ratio is expressed by equation (22) [3] 


$$
\mathrm{I}=\frac{\mathrm{P}_{\mathrm{T}} \mathrm{G}}{\mathrm{N}_{0} \mathrm{R}}
$$

Where $\mathrm{P}_{\mathrm{T}}$ is the transmit power, $\mathrm{G}$ is the channel gain, $\mathrm{N}_{0}$ is unilateral power spectral density of noise (can be taken as 1), and $\mathrm{R}$ is the symbol rate. QPSK modulation is used, so the symbol rate is $1 / 2$ of the information rate $R_{b}$. If $R_{b}$ reduces, the signal-to-noise ratio will increase, and the bit error rate will reduce. Since the cloud, fog and rain fading channel is uncertain, we should estimate the gain G. Its estimation formula is [3]

$$
\widehat{\mathrm{G}}=\mathrm{e}^{\mathrm{m}+\frac{\mathrm{a}^{2} \sigma^{2}}{2}}
$$

In the formula, the parameters $m$ and $\sigma^{2}$ are the mean and variance of the random variable $X=\ln G$, respectively, $a$ is the fading factor, $\mathrm{a}=\mathrm{e}^{-\mathrm{w}_{d} \mathrm{~T}_{\mathrm{d}}}=\mathrm{e}^{-\Pi f_{\mathrm{d}} \mathrm{T}_{\mathrm{d}}}, \mathrm{f}_{\mathrm{d}}$ is Puls frequency shift in fading channel. $\mathrm{T}_{\mathrm{d}}$ is the symbol sampling interval, $0<\mathrm{a}<1$.

To let the difference between the estimated channel gain and the real channel gain as small as possible, a correction margin $\mathrm{K}$ is introduced, and its expression is [3].

$$
\mathrm{K}=\left[\mathrm{e}^{\mathrm{m}} / \mathrm{G}_{\text {out }}\right]^{\sqrt{1-\mathrm{a}^{2}}}
$$

Where $\mathrm{G}_{\text {out }}$ is the threshold of channel gain, $G_{\text {out }}=\mathrm{e}^{\mathrm{m}-\sigma \mathrm{Q}^{-1}\left|\mathrm{P}_{\text {out }}\right|}, \mathrm{Q}(\mathrm{x})=1 / 2 \operatorname{erfc}(\mathrm{x} / \sqrt{2})$, and $\mathrm{P}_{\text {out }}$ is the outage probability of the system.

The estimated value of the signal-to-noise ratio is [3]

$$
\hat{\mathrm{I}}=\frac{2 \mathrm{P}_{\mathrm{T}} \widehat{\mathrm{G}}}{\mathrm{N}_{0} \mathrm{R}_{\mathrm{b}} \mathrm{K}}
$$

Let the maximum transmission rate of the Ka-band satellite communication system be $\mathrm{R}_{\max }$, and we can obtain the estimated signal-to-noise ratio $\hat{\mathrm{I}}_{\mathrm{R}_{\max }}$ from equation (26) at the maximum information rate under the cloud-fog-rain channel under adaptive power control.

$$
\hat{\mathrm{I}}_{\mathrm{R}_{\max }}=\frac{2 \mathrm{P}_{\mathrm{T}} \widehat{\mathrm{G}}}{\mathrm{N}_{0} \mathrm{R}_{\max } \mathrm{K}}
$$

Outage probability of the satellite system should be $0.01 \%$. According to [4], the bit error rate should be $10^{-7}$. Assuming that the corresponding signal-to-noise ratio is $\hat{\mathrm{I}}_{0}$, the signal-to-noise ratio after rate diversity compensation should be no less than $\hat{I}_{0}$. According to [4], [5], $\hat{\mathrm{I}}_{0}$ can be obtained by simulating the error rate of the channel under adaptive power compensation. Then, we can calculate the ratio of SNR [6].

$$
\Delta \hat{\mathrm{I}}=\frac{\hat{\mathrm{I}}_{\mathrm{o}}}{\hat{\mathrm{I}}_{\mathrm{R}_{\max }}}=\frac{\frac{2 \mathrm{P}_{\mathrm{T}} \widehat{\mathrm{G}}}{\mathrm{N}_{0} \mathrm{R}_{\mathrm{b}} \mathrm{K}}}{\frac{2 \mathrm{P}_{\mathrm{T}} \widehat{\mathrm{G}}}{\mathrm{N}_{0} \mathrm{R}_{\max } \mathrm{K}}}=\frac{\mathrm{R}_{\max }}{\mathrm{R}_{\mathrm{b}}}
$$

From equation (27), we could obtain that the adjustment of the information rate $\mathrm{R}_{\mathrm{b}}$ is related to $\Delta \hat{\mathrm{I}}$

\section{B. Dynamic Compensation Achieved by Speed Diversity Technology}

From equation (27) we can obtain,

$$
\mathrm{N}_{0}=\frac{2 \mathrm{P}_{\mathrm{T}} \widehat{\mathrm{G}}}{\mathrm{R}_{\mathrm{b}} \mathrm{K} \hat{\mathrm{I}}}
$$

Let the demodulation threshold of the link transmission error rate $\mathrm{p}_{\mathrm{e}}$ be $\left(\mathrm{C} / \mathrm{N}_{\mathrm{o}}\right)_{\min }$.

When the link availability is $A_{T}$, the rain attenuation is $L_{r}$, and the lowest level is [7].

$$
\mathrm{C}_{\min }=\left(\mathrm{C} / \mathrm{N}_{\mathrm{o}}\right)_{\min }-\mathrm{L}_{\mathrm{r}}+\mathrm{N}_{\mathrm{o}}+\mathrm{M}_{\mathrm{c}}
$$

$\mathrm{M}_{\mathrm{c}}$ is the link margin under clear-sky conditions. $\mathrm{N}_{\mathrm{o}}$ is the link noise power spectral density. $\mathrm{C}$ is the link signal level.

Substituting equations (22) and (28) into (29)

$\mathrm{C}_{\min }=\left(\frac{\mathrm{CR}_{\mathrm{b}} \mathrm{K} \hat{\mathrm{I}}}{2 \mathrm{P}_{\mathrm{T}} \widehat{\mathrm{G}}}\right)_{\min }{ }^{-}$

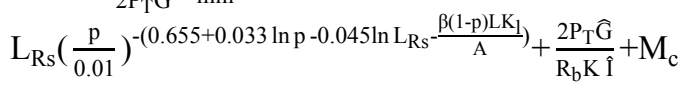

Fixed compensation is applied in downlink, and dynamic rain attenuation compensation can be used in uplink.

From [3], we know that if the rainfall attenuation of the frequency $f_{1}$ is $A_{1}$, the rainfall attenuation $A_{2}$ of the frequency $f_{2}$ can be obtained from the formula.

$$
\mathrm{A}_{2}=\mathrm{A}_{1}\left(\varphi_{2} / \varphi_{1}\right)^{1-\mathrm{H}\left(\varphi_{2} * \varphi_{1}{ }^{*} \mathrm{~A}_{1}\right)}
$$

where $\varphi_{2}, \varphi_{1}$ are the frequency, and $f_{1}, f_{2}$ are rainfall attenuation parameters.

$$
\begin{gathered}
\varphi(f)=\frac{\mathrm{f}^{2}}{1+10^{-4 \mathrm{f}^{2}}} \\
\mathrm{H}\left(\varphi_{2}, \varphi_{1}, \mathrm{~A}_{1}\right)=1.12 * 10^{-3} *\left(\varphi_{2} / \varphi_{1}\right)^{0.5}\left(\varphi_{1} \mathrm{~A}_{1}\right)^{0.55}
\end{gathered}
$$

The value of $f_{1}, f_{2}$ range from 7 to $55 \mathrm{GHz}$. The Ka-band link frequency ranges from 19 to $31 \mathrm{GHz}$.

Therefore, this formula can be used for uplink rain attenuation compensation. However, the statistical formula in [3] is a fitting of the rainfall attenuation relationship, of all frequencies from 7 to $55 \mathrm{GHz}$ and of various environments. There are fitting errors and statistical errors in specific frequencies and positions.

According [8], channel interference, noise, satellite transmitter gain variation, earth station device gain variation might also change in the downlink level. Regardless of changes in downlink level caused by these factors, false compensation might occur when compensating the uplink by the cloud, fog and rain attenuation. What's worse, the satellite transponder may be saturated or damaged. 
While downlink level measured in real time compensates the variation in earth station downlink device gain in the telemetry determination, we can compare the reception level and the level change threshold $\mathrm{L}_{\mathrm{t}}$, the level threshold $\mathrm{S}_{\mathrm{t}}$ and level change duration threshold $\mathrm{T}$. If the level is changed by the cloud, fog and rain attenuation, the uplink level compensation value $A_{u}$ can be obtained from the downlink level attenuation value, and the uplink power is adjusted.

The value of $L_{t}$ is determined by the satellite power stability $L_{s}$, channel interference $L_{i}$, noise $L_{n}$, and multipath attenuation $\mathrm{L}_{\mathrm{m}}$. The threshold is set to avoid adjusting the uplink power caused by downlink level fluctuation from channel interference, noise, multipath fading, etc. [8]

$$
\mathrm{L}_{\mathrm{t}}=\left(\mathrm{L}_{\mathrm{s}}^{2}+\mathrm{L}_{\mathrm{n}}^{2}+\mathrm{L}_{\mathrm{i}}^{2}+\mathrm{L}_{\mathrm{m}}^{2}\right)^{1 / 2}
$$

$\mathrm{S}_{\mathrm{t}}$ is the minimum level value of start control with uplink compensation. It is determined by the link demodulation threshold $\left(\mathrm{C} / \mathrm{N}_{\mathrm{o}}\right)_{\min }$ and the link margin $\mathrm{M}_{\mathrm{c}}$. By setting the threshold people can avoid adjusting the uplink power caused by downlink level fluctuations caused by tracking errors, ionospheric changes, etc. People only adjust the uplink power only when the link signal-to-noise ratio is close to or lower than the demodulation threshold that affects the link transmission error rate [8]

$$
\mathrm{S}_{\mathrm{t}}=\left(\mathrm{C} / \mathrm{N}_{\mathrm{o}}\right)_{\min }+\mathrm{N}_{\mathrm{o}}+\mathrm{M}_{\mathrm{c}}
$$

Substitute equations (22) and (28) into equation (35)

$$
\mathrm{S}_{\mathrm{t}}=\left(\frac{\mathrm{CR}_{\mathrm{b}} \mathrm{K} \hat{\mathrm{I}}}{2 \mathrm{P}_{\mathrm{T}} \widehat{\mathrm{G}}}\right)_{\min }+\mathrm{M}_{\mathrm{c}}+\frac{2 \mathrm{P}_{\mathrm{T}} \widehat{\mathrm{G}}}{\mathrm{R}_{\mathrm{b}} \mathrm{K} \hat{\mathrm{I}}}
$$

Frequent adjustment of uplink power caused by short-term fluctuations in the downlink can be avoided by setting the threshold of the minimum time interval $\mathrm{T}$ for compensation [8]

$$
\mathrm{T}=\max \left(\mathrm{T}_{\mathrm{m}}, \mathrm{T}_{\mathrm{n}}, \mathrm{T}_{\mathrm{i}}, \ldots\right)
$$

Where $T_{m}$ is the maximum value of the level fluctuation duration caused by multipath, $\mathrm{T}_{\mathrm{n}}$ is the random interference duration, and $T_{i}$ is the duration of the flicker noise.

The dynamic compensation accuracy is mainly related to the measurement error of the downlink level $\sigma_{\mathrm{dm}}$, conversion error $\sigma_{\mathrm{c}}$ from cloud, fog and rain attenuation value in downlink level and the cloud, fog and rain attenuation value in uplink level, short-term stability in satellite power $\sigma_{\mathrm{s}}$, control error in uplink power $\sigma_{\mathrm{uc}}$ and so on. They can be determined by experiment, while $\sigma_{c}$ is determined by long-term statistic data. The total compensation error $\sigma$ is [8]

$$
\sigma=\left(\sigma_{\mathrm{dm}}^{2}+\sigma_{\mathrm{c}}^{2}+\sigma_{\mathrm{s}}^{2}+\sigma_{\mathrm{uc}}^{2}\right)^{1 / 2}
$$

In general, $\sigma_{\mathrm{dm}}$ is $0.1 \sim 1 \mathrm{~dB}, \sigma_{\mathrm{s}}$ is $0.2 \sim 1 \mathrm{~dB}, \sigma_{\mathrm{c}}$ is $0.1 \sim 1 \mathrm{~dB}$, and $\sigma_{\mathrm{uc}}$ is $0.1 \sim 0.5 \mathrm{~dB}$. According to the maximum value, the total error of cloud and rain attenuation compensation of this method $\sigma$ is $1.8 \mathrm{~dB}$.

\section{APPLICATIONS}

With the cloud, fog and rain attenuation compensation strategy obtained above, the uplink rain attenuation compensation can be performed with data of a Ka-band communication earth station in Beijing on July $3^{\text {rd }}, 2016$. The measured data of the uplink and downlink rain attenuation is shown in Figure 1. From 6:58 to 8:53, the highest link level attenuation value was $18.63 \mathrm{Db}$. The link level attenuation value was no more than $3 \mathrm{Db}$ when there was no rain. According to [8], in dynamic compensation, when $\mathrm{L}_{\mathrm{t}}=1 \mathrm{~dB}, \mathrm{~S}_{\mathrm{t}}=0 \mathrm{~dB}$, and $\mathrm{T}=$ $60 \mathrm{~s}$. The uplink cloud, fog and rain attenuation compensation result is shown in Figure 2.

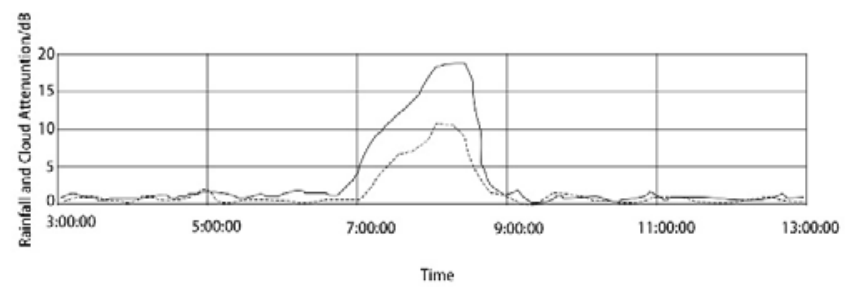

FIGURE. I. CLOUD, FOG AND RAIN ATTENUATION ON THE UPLINK AND DOWNLINK OF KA-BAND EARTH STATION IN A CERTAIN AREA OF BEIJING. SOLID LINE INDICATES UPLINK, DASHED LINE INDICATES DOWNLINK

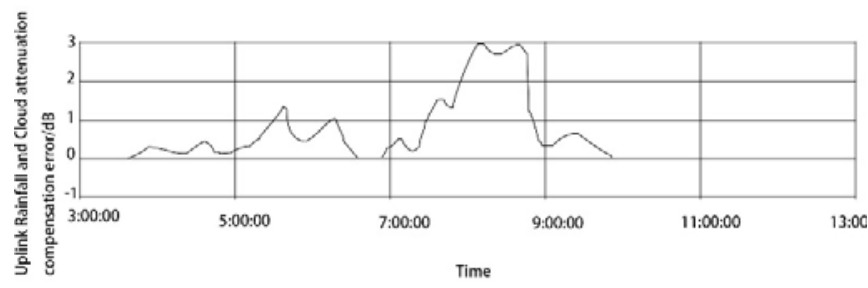

FIGURE. II. UPLINK CLOUD FOG RAIN ATTENUATION COMPENSATION

FIGURE. I and FIGURE. II indicate that, when no compensation is performed, the uplink cloud, fog and rain attenuation is up to $18.64 \mathrm{Db}$. When compensation is performed, the uplink attenuation is $2.91 \mathrm{Db}$. This is the compensation error.

It can be obtained from [9] that this compensation has better effect than the compensation of the American Advanced Communication Satellite System (ACTS), whose compensation error is $5 \mathrm{~dB}$.

\section{CONCLUSIONS}

This paper describes the calculation method of cloud, fog and rain attenuation in Ka-band satellite communication link and applies rate diversity technology for dynamic compensation. In practice, it can effectively reduce the compensation error and ensure reliable transmission of information.

\section{REFERENCES}

[1] ITU.ITU-R P.840-3, Attenuation due to Clouds and Fog [s].1999.

[2] ITU.ITU-R P.618-7, Propagation Data and Prediction Methods Required for the Design of Earth-Space Telecommunication Systems [s].2007.

[3] Milica Stojanovic, and Vincent Chan, Adaptive Power and Rate ControI for Satellite Communications in Ka Band[c]// Proceedings of the IEEE International Conference on Communications. London, UK:IEEE, 2002:2967-2972 
[4] Spiros Ventouras, Iflok Otung, and Charles Wrench, Simulation of Satellite Systems 0perating at Ka-Band and above Using Experimental Time Series of Tropospheric Attenuation [C] // IEE Seminar and Exhibition on simulation and Modelling of Satellite Systems. Pontypridd, UK:IEEE, 2002: 11/1-11/5.

[5] Aihua Wang, and Weixiong Luo, Modelling of Ka Band Satellite Communication Channel and System Performance Simulation [J]. Journal on Communications, 2001, 22(9):61-69.

[6] Miao Yu, and Jian Kang, Mixed Rain Attenuation Compensation Algorithm of Ka-Band Satellite Communication System[J]. Journal of Jilin University, 2015, 33(1):33-38.

[7] Zhengan Zhai, and Chaojing Tang, Ka-band satellite communication link rain attenuation countermeasure $[\mathrm{J}]$. Chinese Space Science and Technology, 2010, 6(3):55-61.

[8] ITU.ITU-R P.837-3, Characteristics of Precipitation for Propagation Modeling[s]. 2007.

[9] Zhaoqing Zhou, Study of rain attenuation of Ka-band satellite communication system[J]. Radio Communications Technology, 2006(5):34-38. 